\title{
Adesão dos docentes universitários aos recursos da web 2.0 para disseminação e compartilhamento da informação e do conhecimento
}

\section{Adhesion of university teachers to web 2.0 resources for information and knowledge dissemination and sharing}

\author{
Maíra Prado ${ }^{1}$; Leticia Gorri Molina ${ }^{2}$
}

\section{Resumo}

A presente pesquisa analisou a adesão dos recursos da Web 2.0 pelos docentes dos cursos de Biblioteconomia na região Sul do Brasil, como forma de compartilhar e disseminar Informação e Conhecimento (I\&C). O procedimento metodológico utilizado foi a pesquisa descritiva com a aplicação do questionário para os docentes do curso de Biblioteconomia. Os resultados apontam os recursos da Web 2.0 utilizados para auxiliar na realização de suas ações, canal de comunicação com o público interno e externo, compartilhar e disseminar I\&C com os discentes e os pares. Além disso, os docentes utilizam as ferramentas como recursos estratégicos para subsidiar e ofertar respaldo nas disciplinas lecionadas nos cursos de Biblioteconomia. Notou-se que as atividades realizadas pelos docentes estão direcionadas na busca pela informação e a maioria dos docentes não são colaboradores na Web. O incentivo ao uso dos recursos para os discentes estão voltados para utilização em sala de aula e formação profissional. A Web 2.0 contribui para promover a interação social, na qual a informação e o conhecimento podem ser produzidos, disseminados e utilizados de modo compartilhado.

Palavras-chave: Web 2.0. Recursos da Web 2.0. Compartilhamento de informação. Compartilhamento de conhecimento. Docentes.

\begin{abstract}
The present study analyzed the adhesion of Web 2.0 resources by teachers of Library Science courses in Southern Brazil in order to share and disseminate Information and Knowledge (I \& K). The methodological procedure used was descriptive research with the administration of a questionnaire to teachers of Library Science course. The results indicate that Web 2.0 resources are used to assist in carrying out their actions, to work as a channel of communication with internal and external audiences, to share and disseminate I \& K with students and peers. In addition, teachers use the tools as strategic resources to assist and offer support in the disciplines taught in Library Science courses. It was noted that activities performed by teachers are aimed at searches for information and most teachers are not Web collaborators. The incentive for the use of resources for the students is aimed at classroom and professional training use. Web 2.0 helps promote social interaction in which information and knowledge can be produced, disseminated and used in shared mode.

Keywords: Web 2.0. Web 2.0 resources. Information sharing. Knowledge sharing. University teachers.
\end{abstract}

${ }^{1}$ Graduada em Biblioteconomia pela Universidade Estadual de Londrina em 2010. Email: mairaprados@gmail.com

2 Mestres pela Universidade Estadual Paulista (Unesp) e Docente do Departamento de Ciência da Informação da Universidade Estadual de Londrina. Email: leticiamolina@uel.br 


\section{Introdução}

A informação e o conhecimento (I\&C) são as principais fontes de riqueza e bens econômicos, o que implica a necessidade de adquiri-los (LÉVY, 1996).

É evidente que com grande fluxo de informação e investimentos em pesquisa, a I\&C torna-se defasada em um curto espaço de tempo. Mas com o uso de ferramentas tecnológicas, estas possibilitaram a disseminação da I\&C atualizadas.

As mudanças ocorridas na Web evidenciaram uma nova plataforma, a Web 2.0, que apresenta maior colaboração dos usuários e condições amplas para o relacionamento e compartilhamento de informação.

Segundo Primo (2007), a Web 2.0 tem o intento de proporcionar a potencialidade nas formas de publicação, compartilhamento e organização de informações, além do mais, estende o ambiente para a interação entre participantes do sistema.

Com um novo campo para explorar o seu potencial, alguns recursos da geração Web 2.0 são relatados na literatura como exemplos. Entre eles, Wikis, Del.icio.us, RSS, Flickr, Blogs, Twitter, Second Life entre outros. A partir de inúmeros recursos oferecidos, o usuário pode compartilhar textos, fotos, vídeos e também outros tipos de arquivos ou, ainda, interagir, participar e realizar leituras, correções e outras ações que o sistema permita.

A Web 2.0 gerou alterações na capacidade crítica e ativa dos usuários que utilizam os recursos da Web 2.0 como recursos de comunicação. A facilidade de publicar, possibilitou criar comunidades que possuem interesses em comuns, que levam as relações interpessoais e fortalece as comunidades. Com maior número de pessoas envolvidas na produção de conteúdo na $W e b$, será maior a qualidade dos serviços, pois essas pessoas atualizam e validam os conteúdos (SIMÃO, 2006).
A comunidade universitária, especialmente os docentes, desenvolvem ações como divulgar e socializar o conhecimento por meio das produções científicas, técnicas culturais; capacitar e atualizar de modo científico e didático-pedagógico (UNIVERSIDADE FEDERAL DE SANTA MARIA, 2009).

Há poucos estudos voltados para a identificação de recursos da Web 2.0 para professores Universitários. Assim, nesta pesquisa, buscou-se analisar a adesão aos recursos da Web 2.0 pelos docentes do curso de Biblioteconomia da região Sul do Brasil para disseminar e compartilhar I\&C. Também foi diagnosticado se os docentes dos departamentos de Ciência da Informação são usuários/ produtores de informação da Web 2.0; identificou qual o uso que os docentes dos departamentos de Ciência da Informação fazem dos recursos da Web 2.0 e levantou os recursos utilizados pelos docentes para adquirir e compartilhar I\&C na Web 2.0.

\section{Revisão de Literatura}

"Compartilhar é o verbo do momento" segundo uma jornalista do Jornal o Globo, essa frase expressa o grande número de usuários da Web que estão compartilhando arquivos (SILVA, 2002). A prática de compartilhar arquivos, que pode ser em formato de vídeo, imagem, sonoro entre outros, mais comuns atualmente. A criação de redes sociais e os recursos da Web 2.0 facilitou a troca de objetos digitais e o mais importante, a troca de informação.

Davenport e Prusak (1998) definem o compartilhamento de informação como uma ação voluntária de disponibilizar a informação com outros indivíduos. Para que exista o compartilhamento de informação, independente das áreas envolvidas é necessário criar ou utilizar ferramentas que permitam a disseminação da informação.

Percebemos no contexto atual a utilização de tecnologia em ambientes institucionais, 
corporativos, educacionais entre outros, que permitem potencializar a produção, o acesso e o uso da informação e conectar pessoas que estejam situadas em diversas localidades, quebrando as barreiras geográficas.

Dentre as ferramentas utilizadas para gerenciar e proporcionar o compartilhamento de informação, pode-se citar a utilização de software proprietários e livres, criação de Websites, comunidades virtuais, listas de discussões, salas de bate papo, recursos da Web 2.0, entre outros (LIMA; SANTINI, 2007).

Diversas informações, objetos digitais em diferentes formatos estão disponíveis na $W e b$ e se difundem nas redes sociais. As pessoas trabalham, estudam, pesquisam e se comunicam com outras, independente de barreira geográfica.

\section{Redes sociais}

As redes sociais disponíveis na $W e b$ estão se desenvolvendo de forma exponencial, permitindo a formação de comunidades que tenham o mesmo interesse em algum objeto de estudo que tendem cada vez mais construir, difundir e disseminar conteúdos.

Marteleto (2001, p. 72) conceitua redes sociais como "[...] um conjunto de participantes autônomos, unindo ideias e recursos em torno de valores e interesses compartilhados". Já Recuero (2005, p. 4) propõe que "[...] uma rede social é formada por dois elementos, os atores (pessoas, instituições ou grupos que formam os nós da rede) e suas conexões (as relações que se estabelecem entre os indivíduos)."

Segundo Tomaél (2007, p. 12), “A proliferação da informação em grupos é comum nas redes, isto em virtude dos atores aproximarem-se de indivíduos que lhes inspirem confiança, ou tenham relações de amizade em muitos casos relações profissionais também". Diante deste argumento, o sujeito se caracteriza por possuir diversas relações, que podem ser motivadas pela amizade, pelas relações de trabalho ou pela simples troca de informações.
As análises de redes podem ser utilizadas para o estudo dos movimentos sociais mais abrangentes (MARTELETO, 2001), para o entendimento das redes temáticas ou de relacionamentos informais, ou, ainda, de relacionamentos técnicos (ACIOLI, 2007). No entanto, a análise nas redes não ocorre apenas no mundo físico, mas também no mundo virtual, por meio das comunidades on-line e nas redes de relacionamento (ACIOLI, 2007).

Os sites de redes sociais como o Orkut, Facebook, Twitter, entre outros, permitem realizar análises para verificar e entender as maneiras que os atores estão se agrupando, como essas redes estão se formando, como essas conexões estão se estabelecendo (SILVA, 2009).

Recuero (2009, p. 121) por meio das ideias de Boyd e Ellison define os sites de redes sociais como sistemas que apresentam três características: “[...] i) a construção de uma persona através de um perfil ou página pessoal; ii) a interação através de comentários e iii) a exposição pública da rede social de cada ator".

A motivação do indivíduo em redes sociais na internet se concretizam por diversos fatores, nos quais envolvem reciprocidade, laço social e reputação social. Henriques (2009) aponta esses fatores:

- Reciprocidade: quando o indivíduo troca informações e constrói reflexões acerca de diversos assuntos, possibilita a troca mútua de informação.

- Laço Social: é formado pelos indivíduos por meio das conexões em redes sociais. Esses laços, desenvolvidos pelos indivíduos, podem ser fortes (maior aproximação entre os sujeitos) e fracos (distância geográfica), e isso depende da participação do indivíduo na interação. O laço social também pode revelar o grau de confiabilidade dos indivíduos.

- Reputação Social: pode ser entendida como a percepção que um indivíduo tem do outro no contexto das redes, e é criada a partir das formas 
como eles se representam. Ou seja, o indivíduo procura produzir e disponibilizar conteúdos na Web para ter maior visibilidade, porém essa situação pode ser consciente ou inconsciente.

Os três fatores descritos são fundamentos essenciais para a formação e consolidação de redes sociais, que podem ser observados nas interações que ocorrem nas diversas ferramentas criadas na internet. $\mathrm{O}$ acesso a esses tipos de sites pode demonstrar a necessidade que os indivíduos têm de se comunicar e trocar informação (HENRIQUES, 2009).

As redes sociais estão ganhando por possibilitarem o compartilhamento de informação de modo rápido, e isso atrai cada vez adeptos, que utilizam essas redes com diversos objetivos.

\section{Recursos da Web 2.0}

A Web 2.0 pode ser compreendida como uma mudança dentro da revolução das Tecnologias da Informação e da Comunicação (TIC), e a transformação social mais relevante da geração da Web 2.0 está centrada na participação dos usuários como criadores e membros ativos da comunidade (MOURA, 2007, p. 3).

Segundo Blattmann e Silva (2007, p. 198):

A web pode ser considerada uma nova concepção, pois passa agora a ser descentralizada e na qual o sujeito torna-se um ser ativo e participante sobre a criação, seleção e troca de conteúdo postado em um determinado site por meio de plataformas. Nessas ambientes, os arquivos ficam disponíveis on-line, e podem ser acessados em qualquer lugar e momento, ou seja, não existe a necessidade de gravar em um determinado computador os registros de uma produção ou alteração na estrutura de um texto. As alterações são realizadas automaticamente na própria $w e b$.

O surgimento da Web 2.0, fez com que muitos estudiosos desenvolvessem recursos que aproximassem as pessoas. Algumas ferramentas já existiam antes da consolidação da Web 2.0, no entanto, com a concretização da mesma, passou a ganhar força e destaque como fortes meios de comunicação, junto com os outros recursos que foram surgindo. Muitos se tornaram grandes conhecidos dos usuários da web, como Wikis, Blogs, Twitter, You Tube, entre outros citados nessa pesquisa.

As Wikis estão se tornando recursos cada vez mais difundidos na internet. Segundo Schmitt (2006, p. 1) Wikis:

Consistem em ambientes que permitem a construção coletiva de hipertextos de forma muito rápida e simplificada, não exigindo dos colaboradores conhecimento especializado de construção de páginas. Outra característica dos wikis é o dinamismo das páginas produzidas e a liberdade de alterar o que existe e acrescentar novas páginas.

A Wiki é uma ferramenta colaborativa na $W e b$ onde possibilita que várias pessoas, dispersas geograficamente possam participar da criação e edição de um texto simultaneamente. Além disso, possibilita a criação e a edição coletiva de textos, propicia a complementação de ideias já descritas, correção de informações desatualizadas ou falsas, permite a exclusão de registros por qualquer participante do processo (SCHWEITZER, 2008).

Já o Blog, segundo Primo e Recuero (2003, p. 55), "são sistemas de publicação na Web, baseados nos princípios de microconteúdo e atualização frequente [...]." Os autores ainda relatam que o sistema ganhou popularidade devido a facilidade para a publicação de informação, uma vez que o usuário não precisa ter conhecimentos em linguagem HTML para publicar no blog.

O Youtube, para Serrano e Paiva (2008, p. 3) “[...] consiste em um serviço de publicação de vídeos que proporciona aos participantes e visitantes a possibilidade de compartilhar e comentar clipes de vídeo", ou ainda "[...] é um site de difusão e compartilhamento de arquivos audiovisuais que se baseia, principalmente, na participação dos internautas como provedores de conteúdo." (BRESSAN, 2007, p. 2). 
A aceitação do Youtube está relacionada com o pioneirismo no processo de digitalização dos conteúdos audiovisuais e interatividade, pois existem mecanismos no site que permite a submissão de comentários, inscrições, receber notificações de novas postagens dos usuários e a resposta aos vídeos já publicados. Essa comunicação existente entre os usuários do site permite a troca de informação, tendo como objetivo desenvolver o sentimento de comunidade (SERRANO; PAIVA, 2008).

O Twitter é uma ferramenta de microblog, com caráter híbrido entre $b \log$, rede social e mensageiro instantâneo (ORIHUELA, 2007). As principais características do Twitter envolvem os fatos das atualizações serem postadas em ordem cronológica; número máximo de caracteres para postar mensagens (140 caracteres) e a possibilidade do usuário incluir outras fontes, como celular, e-mail, palm, etc. Isso permite que a comunicação se torne mais rápida e que o Twitter possa ser utilizado de maneira sincrônica e assíncronica (ZAGO, 2008).

A adesão do Twitter está relacionada com o fato de unificar a experiência de utilizar a internet. Ao invés de ter muitos programas com funções e destinos diferentes, o usuário pode desempenhar muitas atividades da $W e b$, como acessar informação, conversar publicamente e se relacionar com pessoas, independentemente das barreiras geográficas.

\section{A Pesquisa}

A pesquisa caracterizou-se como uma pesquisa descritiva, analisada dentro da metodologia qualitativo-qualitativo. $\mathrm{O}$ instrumento empregado para a coleta de dados foi o questionário, composto por questões fechadas, semi- abertas e abertas.

Os participantes da pesquisa foram os docentes do curso de Biblioteconomia da Região Sul do Brasil, formada pelos professores da Universidade Estadual de Londrina (UEL); Universidade Federal de Santa Catarina (UFSC); Universidade Estadual de Santa Catarina (UDESC); Universidade Federal do Rio Grande do Sul (UFRGS) e Universidade Federal do Rio Grande (FURG).

Como pré-requisito para a participação da pesquisa, definiu-se que os docentes apresentassem graduação ou especialização na área de Ciência da Informação e lecionassem nos cursos de Biblioteconomia em suas respectivas Universidades.

Para a identificação dos docentes, utilizaram-se os sites das Universidades para localizar os cursos de Biblioteconomia e identificar o corpo docente de cada instituição. Após a identificação dos docentes, verificou-se na plataforma Lattes o endereço profissional e a formação acadêmica, observando se condizia com os princípios propostos para a realização da pesquisa.

Verificou-se a existência de 68 docentes com formação na graduação ou especialização na área de Ciência da Informação. De maneira efetiva, participaram da pesquisa 31 docentes, número que corresponde a $45 \%$ da população da pesquisa.

\section{Resultados}

O gênero feminino ainda é predominante entre os docentes do curso de Biblioteconomia: $84 \%$ dos pesquisados são do gênero feminino e $16 \%$ são do gênero masculino. Este fato ocorre talvez porque elas compõem a maioria dos alunos presentes nos cursos de Biblioteconomia e no mercado de trabalho. Pode ser que em função da interdisciplinaridade e diversidade nos cursos que formam profissionais da informação, haverá uma ampliação no quadro desses profissionais, proporcionando um equilíbrio entre os gêneros (FONSECA; JACON; AZEVEDO, 2005). Também percebe-se maior presença do gênero feminino nos cursos de pós-graduação em Ciência da Informação, e isso reflete no gênero do corpo docente.

Quando analisado a distribuição dos docentes por faixa etária, percebeu-se a maior concentração na faixa acima de 50 anos, representado por $42 \%$ docentes; entre 22 a 29 anos representam 13\%; 
entre 30 a 39 anos correspondem $6 \%$, os de 40 a 49 representam $26 \%$, e os acima de 60 anos correspondem a $13 \%$ docentes.

$\mathrm{Na}$ formação acadêmica, concentra-se o maior nível no doutorado, representado por $55 \%$ docentes; $42 \%$ possuem mestrado e $3 \%$ pós-doutorado.

O grande número de docentes com doutorado e mestrado é um reflexo ou resposta às exigências acadêmicas e as atividades burocráticas vivenciadas pelas Universidades para obterem o credenciamento e recredenciamento dos cursos. De acordo com a Resolução ${ }^{\circ} 3$, de 14 de Outubro de $2010^{3}$ do Ministério da Educação - MEC: "Art. $3^{\circ}$ São condições prévias indispensáveis para orequerimento de credenciamento como universidade: I - um terço do corpo docente, com titulação de mestrado ou doutorado."

Além das instituições terem que atender a essa exigência para que seus cursos possam ser credenciados. Os docentes que almejam criar e manter cursos de pós-graduação em seus departamentos passam por uma criteriosa avaliação da Coordenação de Aperfeiçoamento de Pessoa de Nível Superior - CAPES.

Os resultados da avaliação são expressos pela atribuição de uma nota na escala de " 1 " a "7" nos quais os cursos obterão permissão para funcionar no triênio subsequente (COORDENAÇÃO DE APERFEIÇOAMENTO DE PESSOAL DE NÍVEL SUPERIOR, 2010). Tanto o MEC quanto a Capes, mantém exigências para a abertura de cursos de graduação e pós-graduação, para isso é necessário que os professores se capacitem e mantenham a educação continuada.

Todas as Universidades da Região Sul que possuem o curso de Biblioteconomia foram representadas. A participação do corpo docente das Universidades foi: UEL (42\%), UFSC (19\%), UDESC (10\%), UFRGS (13\%) e FURG (16\%).

\section{Os docentes e os recursos da Web 2.0}

Com a Web 2.0, grandes mudanças ocorreram e estão pautadas num processo contínuo de criação e de partilha, como salientou Richardson (2006). Tanto os professores quanto os alunos, agora podem potencializar o aprendizado, e extrair do ambiente $W e b$, os benefícios oferecidos com as novas ferramentas.

Com o intuito de identificar a importância da Web 2.0 na atuação profissional dos docentes, identificamos que $90 \%$ dos docentes consideram importante a utilização dos recursos da Web 2.0, 7\% não consideram e 3\% não responderam.

Os docentes acreditam que com a evolução da área por meio das novas tecnologias, foi preciso aprender a dominá-las para ofertar serviços e produtos de qualidade aos usuários que se tornam cada vez mais exigentes.

A possibilidade de estender e complementar os conteúdos ministrados nas disciplinas lecionadas facilita a interação com os alunos, que permite aproveitar toda a informação disponível na $W e b$ e buscar desenvolver nos alunos a autonomia na busca pela informação.

A questão da gratuidade também foi apontada pelos docentes. Conforme mencionou Assad (2004), “[...] a redução de gastos é uma das diversas vantagens que a Internet e suas ferramentas da $\mathrm{Web}$ 2.0 trouxeram para atingir o equilíbrio, quanto a satisfação das necessidades de informação, considerando-se o âmbito da relação custobenefício." Mas é necessário ressaltar que há recursos da Web 2.0, que o acesso só é liberado através de pagamento, como o Ning.

A troca de Informação e Conhecimento amplia e permite proximidade com pesquisadores e parceiros de pesquisa, proporcionando maior visibilidade. A $W e b$ se tornou importante meio para

${ }_{3}^{3}$ Dispõe sobre normas e procedimentos para credenciamento e recredenciamento de universidades do Sistema Federal de Ensino. 
ajudar no compartilhamento de ideias e rapidez na disseminação da informação, além de ser um campo de trabalho para os profissionais da informação.

Para Terra e Gordon (2002), a evolução do conhecimento descende do trabalho coletivo e não individual, pois o conhecimento é visto como uma construção social e está vinculado a participação humana.

Questionados acerca do nível de utilização dos recursos da Web 2.0 para adquirir I\&C, percebeuse que $68 \%$ dos docentes utilizam algum recurso. Observa-se que fazem uso dos recursos utilizandoos para a realização de pesquisa, formação e sustentação dos colégios invisíveis. Com a criação e divulgação imediata de novos conhecimentos, os recursos proporcionam o acesso a informações mais imediatas do que os livros e periódicos.

No entanto, torna-se necessário utilizar os recursos da Web com critério e seletividade. O aumento da participação das pessoas como agentes produtores, somadas à facilidade de usos desses recursos, também traz como consequência o amadorismo informacional e exige uma criteriosa avaliação da qualidade da informação, da autoria e a definição pelo canal mais apropriado para a busca da informação.

Alguns docentes relataram que ainda não estão familiarizados com os recursos da Web 2.0. Além disso, falta-lhes tempo para utilizar, pois conciliam a vida pessoal e profissional.

Identificamos que os recursos com maior frequência de uso para compartilhar e adquirir I\&C foram Blogs, Youtube, Wikis, Twitter e Facebook e RSS/ATOM e Orkut respectivamente. Os respondentes também citaram outros recursos para adquirir e compartilhar informação, como o Google Grops, Slideshare, Vimeo e Foursquare.

Esses recursos possuem algumas características semelhantes como colaboração, troca de informação, produção e divulgação de conteúdos na $\mathrm{Web}$, como aponta Schweitzer (2008); Alcará e Curty (2008);
Serrano e Paiva (2008). Essas características podem ser fundamentais na realização das atividades que os docentes propõem a realizar, uma vez que são facilitadoras para adquirir I\&C na Web. No entanto, dois docentes apontaram que não gostam de utilizar os recursos, mas tiveram que se habituar devido às exigências profissionais.

Os principais objetivos para fazerem uso dos recursos citados, envolvem atividades relacionadas com o trabalho (35\%), estudo (33\%) e entretenimento $(28 \%)$.

Verificou-se que $55 \%$ dos docentes não são mantenedores de nenhum recurso e $45 \%$ mantém algum recurso, sendo que os mantenedores relataram que fazem uso para manter conteúdos das disciplinas ministradas e proporcionar um canal de comunicação com a comunidade interna e externa, por meio de Blogs, listas de discussões entre outros.

Já os docentes que não são mantenedores, justificam a falta tempo, pois então envolvidos com cargos administrativos em seus departamentos, processo de formação continuada, como o doutorado e cargos que acarretam excesso de atividades acadêmicas.

Em relação às experiências de utilização dos recursos, $90 \%$ dos sujeitos da pesquisa nunca tiveram problemas e $10 \%$ apontaram a disseminação maciça de spam, perda de informação pela facilidade de atualização no ambiente e ineficiência no sistema de comentário.

Pode-se observar que os recursos da Web são utilizados para disseminar e compartilhar I\&C, apesar de 42\% dos respondentes não incluírem comentários a respeito das informações vinculadas nas ferramentas da $\mathrm{Web}$, e $32 \%$ raramente postarem comentários, ou seja, só quando é solicitado pelo próprio recurso e quanto o assunto for relevante.

Dentre os participantes da pesquisa, 26\% relataram que realizam comentários, pois é uma forma de individualizar a informação. $\mathrm{O}$ diferencial do ambiente web é a possibilidade de interferência 
dos indivíduos, participando e colaborando, que nos meios de comunicação de massa essa interferência é inexistente ou ínfima.

A uma questão acerca da importância da utilização dos recursos da Web 2.0 na aquisição e no compartilhamento de informação para atuação de docentes universitários, percebeu-se que $87 \%$ dos pesquisados consideram essencial a utilização desses recursos.

Para os respondentes, esses recursos possibilitam obter informações atualizadas e incentivam os alunos a discutir no mesmo meio, já que oferecem uma gama de atividades e ampliam o ambiente da sala de aula. Além disso, os docentes podem consolidar rede com os pares e demais profissionais.

$\mathrm{Na}$ literatura, têm-se observado vários estudos sobre a utilização de ferramentas da Web na potencialização das atividades pedagógicas, como: Coutinho e Bottentuit Junior (2007), Carvalho (2008), Almeida (2007). Para tal, 68\% respondentes relataram que essas ferramentas incentivam os discentes a fazer uso de ferramentas da Web 2.0 na sala de aula e na futura carreira profissional.

$\mathrm{Na}$ carreira, o incentivo está relacionado com a troca de experiências profissionais. A possibilidade de gerar uma rede de contatos e criar oportunidades de emprego permite aumentar o contato entre as pessoas e a troca de informação. $\mathrm{Na}$ sala de aula, os recursos estão ligados com a construção coletiva, ao debate, as possibilidades de estender as discussões das matérias lecionadas e potencializar e complementar os conteúdos tratados na disciplina.

Os recursos existentes on-line e as ferramentas de fácil publicação da Web 2.0 estabelecem opções para que professores e alunos possam aprender colaborativamente, divulgando e compartilhando as suas experiências e saberes (CARVALHO, 2008).

Além disso, permite ampliar a rede social, compartilhar informações e atualização de informação. Visando ao mercado de trabalho, os respondentes também apontaram que os futuros profissionais da informação devem agregar valor ao desempenho profissional, especialmente no que diz respeito à Biblioteca 2.0, catálogo 2.0 e ações corporativas.

A Biblioteca 2.0 e suas aplicações é uma nova tendência aderida pelas bibliotecas, pois “[...] está mais centrada em levar a informação para os usuários por intermédio dos serviços e produtos prestados pelas bibliotecas via Internet [...]" (CURRAN et al., 2006 apud BLATTMANN; SILVA, 2007, p. 195). Com um novo ambiente e público, os bibliotecários devem atentar para as novas formas de atendimento, serviços e produtos, para trazer o público mais das unidades de informação.

Assim, os futuros profissionais da informação não terão somente as bibliotecas em ambientes tradicionais, mas sim, em um ambiente que ultrapasse o espaço físico e a insira em um mundo virtual denominado ciberespaço (VIEIRA; CARBALHO; LAZZARIN, 2008).

No entanto, $6 \%$ dos docentes não estimulam os alunos a utilizarem os recursos em nenhum ambiente. Estes justificaram que, como não fazem uso, não recomendam para seus alunos. Verificamos que esses docentes concentram-se na faixa de 50 a 59 anos. Acreditamos que pela faixa etária, esses pesquisados podem encontrar maior dificuldade para utilizarem as ferramentas e até mesmo resistência, as novas tecnologias.

As contribuições das aplicações dos recursos da Web 2.0 na área de Ciência da Informação voltadas para subsidiar a aprendizagem dos alunos foram descritas pelos docentes como responsável por proporcionam outra visão para área de Biblioteconomia. O espaço da biblioteca e de estantes com livros se unem a outras atividades e processos, assim revelando aos estudantes novas ênfases profissionais e espaços de trabalho.

Outra função apontada pelos docentes foi a utilização dos recursos da Web 2.0 para ampliar a ambiente da sala de aula, assim adquirir contato 
com os alunos e a abrangência dos temas abordados na sala de aula, que facilita o processo de ensino e aprendizagem.

Os alunos podem interagir entre si e com os professores em momentos distintos havendo aprendizagem por todos os atores envolvidos. Além de estimulá-los a serem co-participantes da rede e não somente "leitores" e, assim, atribuir uma maior dinâmica aos conteúdos tratados em sala de aula, incluindo visões de profissionais e pesquisadores acerca de temas abordados que muitas vezes não são contemplados na bibliografia da disciplina.

\section{Considerações Finais}

A presente pesquisa mostrou que a maioria dos docentes consideram importante a utilização de recursos da Web 2.0 para o compartilhamento e disseminação de I\&C. A utilização das ferramentas facilita extensão do conteúdo ministrado e permite a troca de informação com os discentes e os pares de maneira rápida.

O uso das novas tecnologias forçou os docentes a adequar-se e aprender a utilizar as ferramentas para potenciar suas atividades, devido às exigências profissionais, principalmente aqueles que lecionam disciplinas que estão direcionadas a área tecnológica.

Os recursos da Web 2.0 permitem dar suporte as atividades práticas nas disciplinas, realização de pesquisa, formação e sustentação dos colégios invisíveis e pelos docentes estarem ligados a cargos administrativos nos departamentos, sendo fundamental criar redes para comunicação com o público interno e externo.

As atividades realizadas pelos docentes através dos recursos da Web 2.0 estão mais centradas na busca da informação do que na criação da mesma, uma vez que os mesmos utilizam mais as ferramentas para buscar as informações inseridas, do que na inserção de informação. Não se pode afirmar que os docentes são colaboradores na $W e b$, visto que há poucos deles que realizam comentários nos recursos. Os docentes permanecem, na maioria das vezes, na posição receptora, ou seja, só adquirem I\&C, mas não participam como contribuidores de conteúdo.

Verificou-se que os docentes estimulam os discentes a utilizar as ferramentas da Web 2.0 na sala de aula, assim como na futura carreira profissional. Na carreira profissional, o incentivo está direcionado para a troca de experiências profissionais, que possibilita ampliar as redes de contatos, as chamadas networks. Na sala de aula, o incentivo está direcionado a construção coletiva, complementar os conteúdos abordados na disciplina e possibilitar discussões ocorridas, tanto neste ambiente, quanto em outro espaço.

Para os docentes, a contribuição dos recursos da Web 2.0 está voltada para subsidiar a aprendizagem e envolve: ampliar a interação além da sala de aula; reaproveitar a informação produzida e indicada nesses ambientes; tornar os alunos participantes da construção desse conhecimento de alguma forma; e ambientar os alunos com o uso destas ferramentas.

A Web, juntamente com os seus recursos, é uma grande fonte de informação da atualidade, principalmente para docentes que necessitam de informações atualizadas para a realização de suas atividades. Portanto, não fazer uso dos recursos da Web 2.0, poderia resultar na subutilização de um meio de disseminar e adquirir I\&C extremamente importante, visto que os recursos permitem a atualização rápida de informação.

O interessante é que os recursos da Web 2.0 sejam usados para ampliar as possibilidades de compartilhamento e disseminação da I\&C, meios de didáticas, e revelar novas áreas de atuação para os discentes que entrarão no mercado de trabalho. Fazer uso dos recursos ou não é uma questão de ação, pois os recursos existem, basta que sejam utilizados de maneira inteligente. 


\section{Referencias}

ACIOLI, S. Redes sociais e teoria social: revendo os fundamentos do conceito. Informação \& Informação, Londrina, v. 12, n. esp., 2007. Disponível em: <http:// www.uel.br/revistas/uel/index.php/informacao/article/ viewFile/1784/1520>. Acesso em: 26 maio. 2010

ALCARÁ, A. R.; CURTY, R. G. Blogs: dos diários egocentristas aos espaços de comunicação científica Web 2.0. In: TOMAÉL, M. I. (Org.). Fontes de informação na internet. Londrina: EDUEL, 2008. p. 81-96.

ALMEIDA, M. E. B. Tecnologia e formação de educações/pesquisadores: do uso do computador na escola aos desafios da Web 2.0. São Paulo: CED/PUCSP, 2007. Disponível em: <http://arquivos.unama.br/nead/fit/ modulo_2 $/ \mathrm{html} / \mathrm{materiais} /$ Tecnologia_e_formacao_de educadores\%20-\%20web2.0.pdf $>$. Acesso em: 26 out. 2010.

ASSAD, R. Beneficios da internet ás empresas. 2004. 132 f. Dissertação (Mestrado em Engenharia de Produção) - Programa de Pós-Graduação em Engenharia de Produção, Universidade Federal de Santa Catarina, UFSC. Disponível em: <http://teses.esp.ufsc.br/defesa/ pdf/12081.pdf $>$. Acesso em: 3 jun. 2010.

BlattManN, U.; SilvA, F. C. C. Colaboração e interação na Web 2.0 e biblioteca 2.0. Revista $A B C$ : Biblioteconomia em Santa Catarina, Florianópolis, v. 12, n. 2, p. 191-215, jul./dez. 2007. Disponível em: $<$ http://revista.acbsc.org.br/index.php/ racb/article/ view/530/664>. Acesso em: 28 set. 2008.

BRESSAN, R. T. Youtube: intervenções e ativismos. In: CONGRESSO BRASILEIRA DE CIÊNCIAS DA COMUNICAÇÃO DA REGIÃO SUDESTE, 12., Juiz de Fora. Anais eletrônicos... Juiz de Fora: Intercom, 2007. Disponível em: <http://www.intercom.org.br/papers/ regionai s/sudeste2007/ resumos/R0040-1.pdf $>$. Acesso em: 2 jun. 2010.

CARVAlHO, A. A. A. (Org.). Manual de ferramentas da Web 2.0 para professores. Portugal: Ministério da Educação: 2008. Disponível em: $<$ http://www.crie.minedu.pt/publico/web20/manual_web20-professores.pdf $>$. Acesso em: 24 out. 2010.

COORDENAÇÃO DE APERFEIÇOAMENTO DE PESSOAL DE NÍVEL SUPERIOR. Avaliação da PósGraduação. 2010. Disponível em: <http://www.capes. gov.br/avaliacao/avaliacao-da-pos-graduacao $>$. Acesso em: 26 out. 2010 .

COUTINHO, C. P.; BOTTENTUIT JUNIOR, J. B. Blog e wiki: os futuros professores e as ferramentas da web 2.0. In; SIMPOSIO INTERNATIONAL DE INFORMATICA EDUCATIVA, 9., 2007, Porto. Anais eletrônicos... Porto:
ESSE-IPP, 2007. Disponível em: <http://repositorium. sdum.uminho.pt/bitstream/1822/7358/1Com\%20SIIE. pdf $>$. Acesso em: 2 jun. 2010.

DAVENPORT, T.; PRUSAK, L. Conhecimento empresarial: como as organizações gerenciam seu capital intelectual. Tradução Lenke Peres. Rio de Janeiro: Campus, 1998.

FONSECA, M.; JACON, M. C. M.; AZEVEDO, M. E. Características sócio-demográficas e inserção do Professional da informação no mercado de trabalho. In: ENCONTRO NACIONAL DE PESQUISA EM CIENCIA DA INFORMAÇÃO, 6., 2005, Florianópolis. Anais... Florianópolis: UFSC, 2005. CR-ROM.

HENRIQUES, S. M. G. Mobile social network: a tecnologia móvel e o avanço das novas redes sociais. In: CONGRESSO BRASILEIRO DE CIÊNCIAS DA COMUNICAÇÃO, 32., 2009, Curitiba. Anais eletrônicos... Curitiba: INTERCOM, 2009. Disponível em: <http://www.intercom.org.br/papers/nacionais/2009/ resumos /R4-2049-1.pdf $>$. Acesso em: 26 maio 2010.

LÉVY, P. O que é virtual? São Paulo: Ed. 34, 1996.

LIMA, C. R. M.; SANTINI, R. M. Trabalho imaterial, compartilhamento de informação e produção colaborativa na sociedade da informação. Encontros Bibli, Florianópolis, n. 23, 1. sem. 2007. Disponível em: $<$ http://www.periodicos.ufsc.br/index.php/eb/article/ viewPDFInterstitial/407/399>. Acesso em: 10 jun. 2009.

MARTELETO, R. M. Análise de redes sociais: aplicação nos estudos de transferência da informação. Ciência da Informação, Brasília, v. 30, n. 1, p. 71-81, jan./abr. 2001. Disponível em: <http://dici.ibict.br/archive/00000204/01/ Ci[1].Inf-2004-261.pdf $>$. Acesso em: 15 maio. 2010.

MOURA, A.A Web 2.0 na aula de língua materna: relato de uma experiência. In: ENCONTRO INTERNACIONAL DISCURSO METODOLOGIA E TECNOLOGIA, 2007, Miranda do Douro [Portugal]. Anais eletrônicos... Miranda do Douro: CEAM, 2007. p. 9-24. Disponível em: <http://adelinamouravitae.com.sapo.pt/index 1.htm>. Acesso em: 23 mar. 2010

ORIHUELA, J. L. Twitter y el boom del microblogging. Perspectivas del Mundo de la comunicación, Navarra, $n$. 43, p. 2-3, nov. 2007. Disponível em: <http://www.unav. es/fcom/perspectivas/pdf/persp43.pdf $>$. Acesso em: 13 jun. 2009.

PRIMO, A. O aspecto relacional das interações na $W e b$ 2.0. E- Compós, Brasília, v. 9, p. 1-21, 2007. Disponível em: <http://www.moodle.ufba.br/mod/resource/view. php?id=18900>. Acesso em: 14 out. 2008. 
PRIMO, A.; RECUERO, R. Hipertexto cooperativo: uma análise da escrita coletiva a partir dos Blogs e da Wikipédia. In: VII SEMINÁRIO INTERNACIONAL DE COMUNICAÇÃO, 7., 2003, Porto Alegre. Anais... Porto Alegre: PUC/RS, 2003.

RECUERO, R. C. Weblogs, webrings e comunidades virtuais. Revista o4nOtFound, Bahia, v. 1, n. 31, ago. 2003. Disponível em: <http://www.bocc.uff.br/pag/ recuero-raquel-weblogs-webrings-comunidades-virtuais. pdf $>$. Acesso em: 12 maio 2010.

RECUERO, R. Comunidades virtuais em redes sociais na internet: uma proposta de estudo. Ecompos, Internet, v. 4, dez. 2005.

2009.

Redes sociais na internet. Porto Alegre: Sulina,

RICHARDSON, W. Blogs, Wikis, podcasts and other powerful web tools for classroom. California: Corvin Press, 2006.

SERRANO, P. H. S. M.; PAIVA, C. C. A nova (Des) ordem da cibercultura noemas de usos, restrição e censura no youtube. In: CONGRESSO BRASILEIRO DE CIENCIAS DA COMUNICAÇÃO, 31., 2008, Natal. Anais eletrônicos... Natal: INTERCOM, 2008. Disponível em: <http://www.intercom.org.br/ papers/ nacionais/2008/resumos/R3-0803-1.pdf $>$. Acesso em: 2 jun. 2010 .

SCHMITT, M. A. R. Dificuldade apresentadas pelo modelo wiki para a implementação de um ambiente colaborativo de aprendizagem. Renote, Porto Alegre, v. 4, n. 2, p. 1-7, dez. 2006. Disponível em: <http://www. cinted.ufrgs.br/renote/dez2006 /artigosrenote/25095. pdf $>$. Acesso em: 10 jun. 2009.

SCHWEITZER, F. O serviço de referencia da biblioteca central da UFSC e o programa de capacitação do usuário: desenvolvimentos de uma ferramenta colaborativa com base na tecnologia wiki. Revista Brasileira de Biblioteconomia e Documentação, São Paulo, v. 4, n. 1, p. 6-19, 2008. Disponível em: <http://www.febab.org.br/ rbbd/ojs-2.1.1/index.php/rbbd/ article/viewFile/91/97>. Acesso em: 2 jun. 2010.

SILVA, T. Compartilhar é a solução. In: SEMINÁRIO NACIONAL DE BIBLIOTECAS UNIVERSITÁRIAS, 12., 2002, Recife. Anais... Recife: UFPE, 2002. Disponível em: <http://www.sibi.ufrj.br/snbu/snbu2002/ oralpdf/138.a.pdf>. Acesso em: 11 abr. 2010.

SILVA, A. C. da. As apropriações nos sites de redes sociais na internet. In: CONGRESSO BRASILEIRO DE CIÊNCIAS DA COMUNICAÇÃO, 32., 2009, Curitiba. Anais eletrônicos... Curitiba: INTERCOM, 2009. Disponível em: <http://www.intercom.org.br/papers/ nacionais /2009/ resumos/R4-1453-1.pdf $>$. Acesso em 26 maio. 2010

SIMÃO, J. Relação entre os Blogs e Webjornalismo. Revista Prisma, Porto, n. 3, out., p.148-164, 2006. Disponível em: <http://prisma.cetac.up.pt/ artigospdf/9joao_simao_ prisma.pdf $>$. Acesso em: 22 jun. 2009.

TERRA, J. C. C; GORDON, C. Portais corporativos: a revolução do conhecimento. São Paulo: Negócio, 2002.

TOMAÉL, M. I. Redes Sociais, conhecimentos e inovação localizada. Informação \&Informação, Londrina, v. 12, n. esp., 2007. Disponível em: <http://www.uel.br/revistas/ uel/index. php/informacao/article/viewFile/ 1782/1519>. Acesso em: 25 maio. 2010.

UNIVERSIDADE FEDERAL DE SANTA MARIA. Dados produção docente. 2009. Disponível em: <http:// w3.ufsm.br/prograd/cesnors2009/ENGENHARIA_ AMBIENTAL/PAPEL\%20DOS\%20DOCENTES.pdf $>$. Acesso em: 28 jun. 2009.

VIEIRA, D. V.; CARVALHO, E. B. de C.; LAZZARIN, F. A. Uma proposta de modelo baseado na Web 2.0 para as bibliotecas das Universidades Federais. In: ENCONTRO NACIONAL EM PESQUISA EM CIÊNCIA DA INFORMAÇÃO, 19., 2008, São Paulo. Anais eletrônicos... São Paulo: USP, 2008. Disponível em: $\quad<$ http://www.bax.com.br/teaching/courses/ bibliotecasdigitais/referencias/PROPOSTA.pdf $>$. Acesso em: 22 out. 2010.

ZAGO, G. Usos sociais do Twitter: proposta de tipologia a partir do capital social. 2008. Disponível em: <http:// jandre.wikispaces.com/file/view/RG3P4.pdf>. Acesso em: 25 maio 2010.
Recebido em: fevereiro de 2011

Aceito em: junho de 2011 
Prado, M.; Molina, L. G. 